\title{
Performance assessment issues in utility-scale photovoltaics in warm and sunny climates ${ }^{\star}$
}

\author{
Ricardo Ruther*, Lucas Rafael do Nascimento, and Rafael Antunes Campos \\ Universidade Federal de Santa Catarina, Caixa Postal 476, Florianópolis, SC 88040-900, Brazil
}

Received: 14 January 2017 / Received in final form: 7 July 2017 / Accepted: 27 July 2017

\begin{abstract}
With the declining costs of photovoltaics (PV), and the excellent solar energy resource availability in the country, the Brazilian government and the electricity sector have started to evaluate and consider PV as a serious potential contributor to the National electricity mix. Since the late 1990s, Brazilian electrical utilities are required by the National Electrical Energy Regulatory Agency ANEEL to invest 1\% of their operational income on R\&D. In 2011, ANEEL issued an R\&D call dedicated to utility-scale PV. The solar energy research group at Universidade Federal de Santa Catarina (www.fotovoltaica.ufsc.br) has been actively investigating and promoting PV in Brazil, operates since 1997 the first grid-connected, thin-film PV generator in the country. Under the ANEEL R\&D call, a 4-year, US\$ 20 million project was started in 2012. The project aims at assessing the performance of seven different PV technologies at eight different Evaluation Sites (ES) in Brazil, and also to design, procure, install and monitor the performance of a utility-scale $3 \mathrm{MWp} R \& \mathrm{D}$ PV power plant, which is located at one of these eight ES. The $3 \mathrm{MWp}$ PV power plant and all the eight ES are fully monitored, with all electrical and environmental parameters measured at 1-s intervals. PV technologies include thin-film amorphous silicon (a-Si), microcrystalline silicon ( $\mu \mathrm{c}-\mathrm{Si})$, cadmium telluride $(\mathrm{CdTe})$, copper indium gallium diselenide, mono- and multi-crystalline silicon (c-Si and $\mathrm{m}$-Si), all at fixed tilt, as well as double-axis tracking, concentrated PV using triple-junction InGap/GaAs/Ge at 820 suns concentration. All ES are identical, except for the fixed $\mathrm{PV}$ arrays tilt angle, which is equal to the latitude at each site. The $3 \mathrm{MWp}$ R\&D PV power plant is co-located at one of the ES sites. Thin-film PV technologies with a low temperature coefficient of power presented superior output performance, and cloud-edge and cloud-enhancement effects of solar irradiance resulted in operational issues that were not previously described in the literature. Inverter Loading Ratios commonly described in the literature (for less sunny sites) led to considerable annual energy losses.
\end{abstract}

\section{Introduction}

The widespread utilisation of solar photovoltaics (PV) in utility-scale, large-area power plants in warm and sunny climates like Australia and Brazil is fairly recent. The influence of high operating temperatures, extreme overirradiance events due to cloud-edge and cloud-enhancement effects [1-8], and soiling [9-12] on the performance of $\mathrm{PV}$ power plants is much more extreme in these countries than in the more temperate climates where most of the $\sim 300 \mathrm{GW}$ of PV operate worldwide [13-20]. The negative temperature coefficient of power of the crystalline silicon and the copper indium gallium diselenide (CIGS) thin-film $\mathrm{PV}$ technologies are both in the order of -0.4 to $-0.5 \% /{ }^{\circ} \mathrm{C}$,

\footnotetext{
^World Renewable Energy Congress XVI, 5-9 February 2017, Murdoch University, Western Australia (Photovoltaic Technologies).

*e-mail: ricardo.ruther@ufsc.br
}

while for the thin-film amorphous silicon and cadmium telluride CdTe PV technologies it is around $-0.2 \% /{ }^{\circ} \mathrm{C}$. High ambient temperatures, associated with high irradiance levels, can lead to PV device operating temperatures in excess of $80^{\circ} \mathrm{C}$ if wind speeds are low, resulting in considerable output losses for all PV technologies. At sites with disperse cloud coverage, cloud-edge and cloudenhancement effects can lead to irradiance levels in excess of $1800 \mathrm{~W} / \mathrm{m}^{2}$. These two effects combined can lead to a cascade of string-box fuse burnings in large-area PV fields if fuses are not properly specified. On the other hand, PV module manufacturer maximum series fuse ratings, designed originally for more temperate climates, are somewhat narrow, and the properly specified fuse for a PV array string box under the operating conditions described above might exceed the particular PV module maximum series fuse rating, voiding PV module warranty. Soiling is also an issue that will affect more the output of large-scale, ground-mounted PV power plants in warm and sunny 


\section{R\&D project: US\$ 20 million}

- 3 MWp R\&D PV power plant, using 3 PV technologies

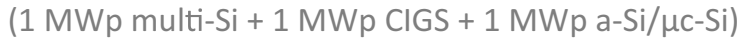

$+$

- 8 identical evaluation sites, located in 8 different

Brazilian climates, using 7 PV technologies each

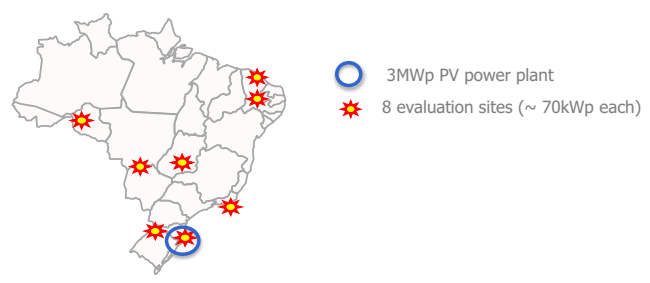

Fig. 1. General location in the Brazilian Territory of the eight identical Evaluation Sites (ES), located between $3^{\circ} \mathrm{S}$ and $28^{\circ} \mathrm{S}$ each with $70 \mathrm{kWp}$ of PV using seven PV technologies, and the $3 \mathrm{MWp}$ R\&D PV power plant using three PV technologies.
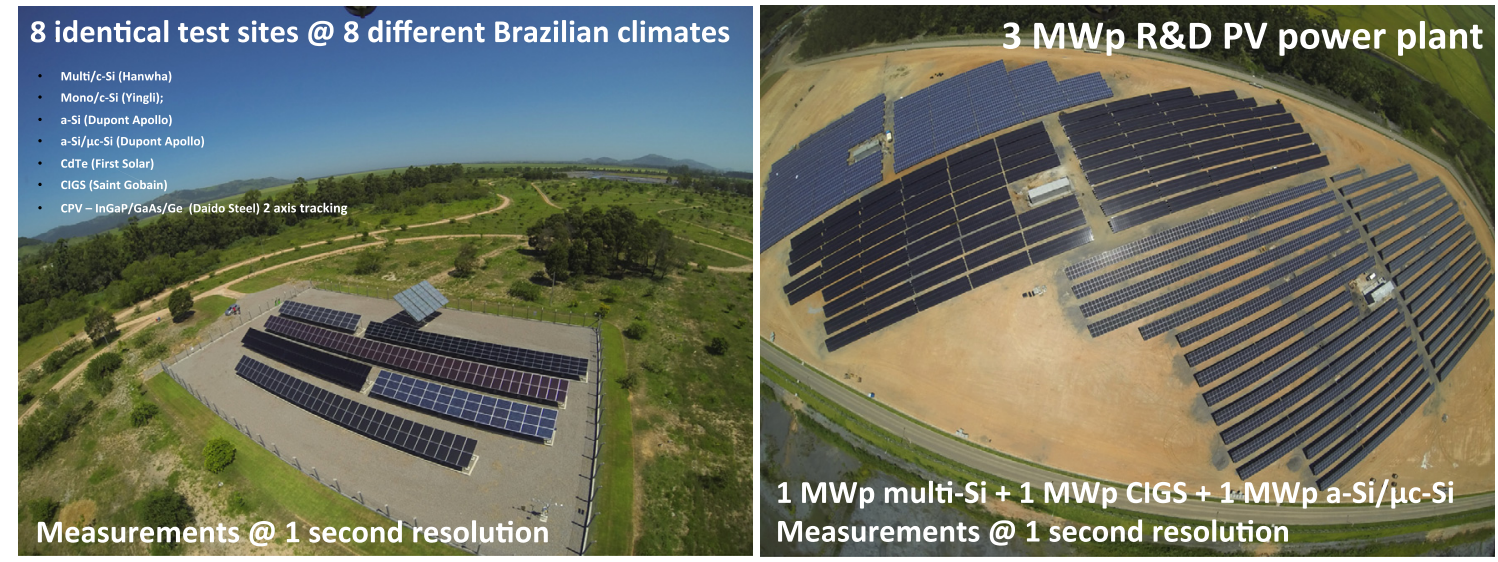

Fig. 2. One of the eight identical Evaluation Sites (ES), with $70 \mathrm{kWp}$ of PV using seven PV technologies (left), and the $3 \mathrm{MWp}$ R\&D $\mathrm{PV}$ power plant using three PV technologies (right).

climates, due to the typical absence of ground cover around PV arrays, with sand and dust accumulating on $\mathrm{PV}$ module surfaces in regions where water for cleaning might not be available. In this project, we have thoroughly assessed the performance of a number of different PV technologies in eight warm and sunny climates in Brazil.

\section{Methodology}

Under a US\$ 20 million R\&D project funded by 12 Brazilian electrical utility companies in the scope of the Brazilian National Regulatory Agency ANEEL (www. aneel.gov.br) R\&D program, eight fully-monitored $70 \mathrm{kWp}$ PV Evaluation Sites (ES), each using seven different, commercially-available PV technologies (single- and multicrystalline silicon, two-axis-tracking 820 suns concentrated $\mathrm{PV}$, and the thin-film PV technologies CdTe, CIGS, a-Si and a-Si $/ \mu \mathrm{c}-\mathrm{Si}$ ), plus a fully-monitored, $3 \mathrm{MWp}$ utilityscale R\&D PV power plant, were installed in Brazil between 2013 and 2014. Figure 1 shows the map of Brazil with the location of the eight ES plus the 3 MWp R\&D PV power plant, and Figure 2 shows an aerial view of (left) one of the eight ES and (right) the $3 \mathrm{MWp}$ R\&D PV power plant. These eight identical ES (the only difference is the module tilt angle for the fixed-tilt arrays at each site, which is equal to the local latitude in each case) are constantly monitored, with irradiance, temperature (ambient and back-of-module) and electrical parameters measured and logged at 1-s intervals. The $3 \mathrm{MWp}$ R\&D PV power plant uses three different commercially-available PV technologies (1 MWp each technology: multi-crystalline silicon, thin-film CIGS and thin-film a-Si/ $\mu$ c-silicon, which are shown from back to front respectively in Fig. 2 - right). Each one of these three $\times 1 \mathrm{MWp}$ fractions is again subdivided: $500 \mathrm{kWp}$ using string inverters and the other $500 \mathrm{kWp}$ using a central inverter. The six subdivisions of the $3 \mathrm{MWp}$ R\&D PV power plant can be clearly seen in Figure 2 (right). High-quality, research-grade and state-ofthe-art irradiance, electrical parameters and temperature measurement devices and dataloggers were used, and a more detailed description of the eight locations, the experimental set up and equipment specifications was presented elsewhere [21]. 

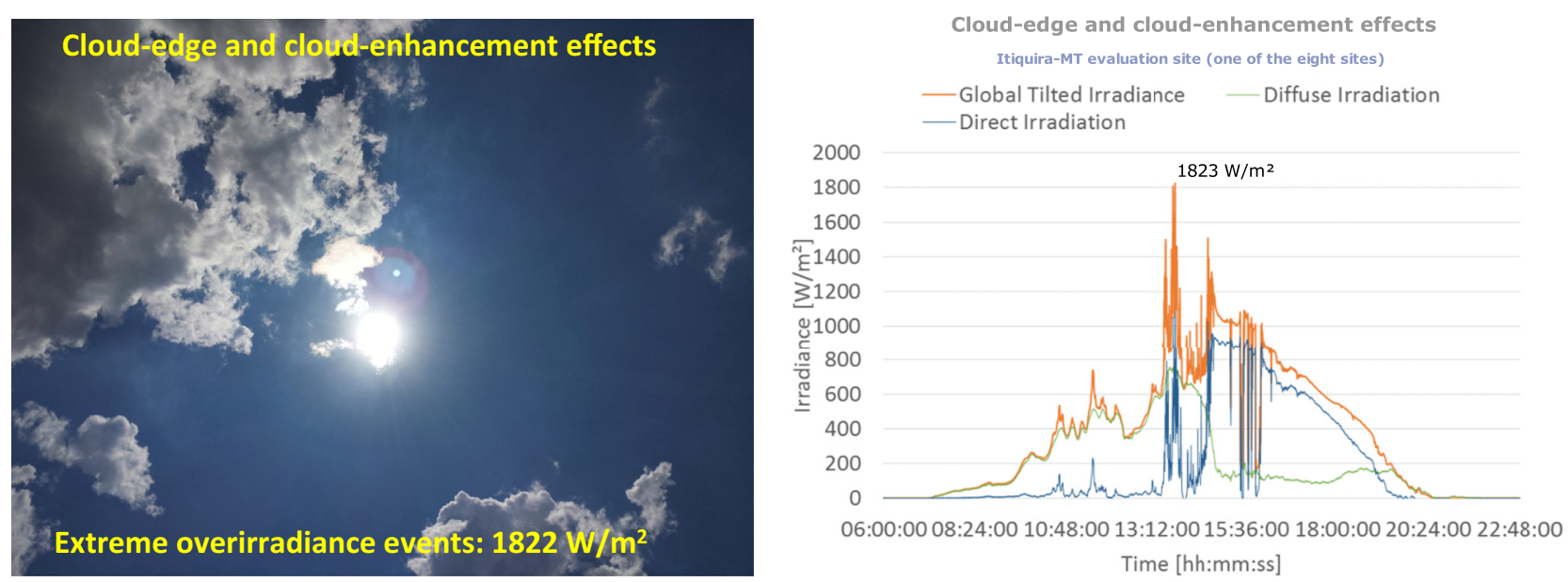

Fig. 3. Cloud-edge + cloud-enhancement overirradiance events at one of the eight Evaluation Sites reported in this paper, in which an irradiance peak of $1823 \mathrm{~W} / \mathrm{m}^{2}$ was measured.

Table 1. Overirradiance events and event duration for irradiance peaks at or above the extraterrestrial irradiance of $1367 \mathrm{~W} / \mathrm{m}^{2}$ registered at one of the eight Evaluation Sites reported in this paper.

\begin{tabular}{lclll}
\hline Duration & Frequency & Frequency $(\%)$ & Maximum irradiance $\left(\mathrm{W} / \mathrm{m}^{2}\right)$ & Average irradiance $(\mathrm{W})$ \\
\hline Less than 5s & 1044 & $31 \%$ & 1557 & 1463 \\
Between 5s and 10s & 727 & $22 \%$ & 1711 & 1559 \\
Between 10s and 30s & 983 & $29 \%$ & 1673 & 1555 \\
Between 30s and 1 min & 337 & $10 \%$ & 1806 & 1573 \\
Between 1 min and 5 min & 259 & $8 \%$ & 1823 & 1649 \\
Greater than 5 min & 24 & $1 \%$ & 1564 & 1511 \\
\hline
\end{tabular}

\section{Cloud-edge and cloud-enhancement effects}

Cachoeira Dourada-GO evaluation site (another of the eight sites)

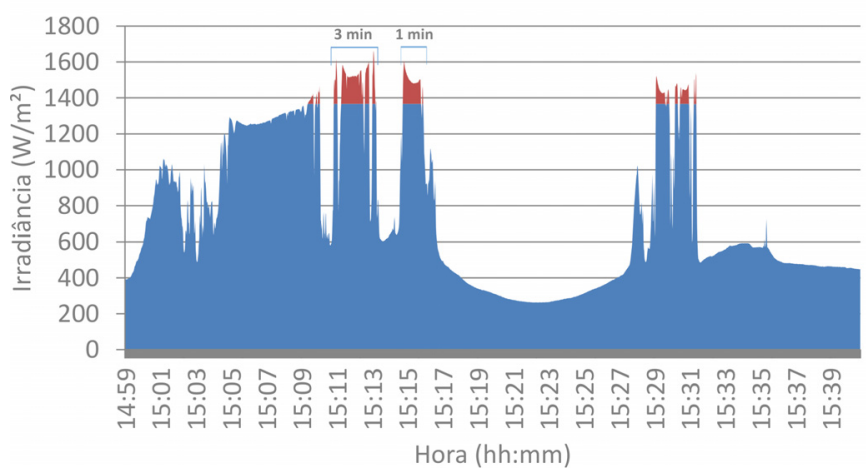

Fig. 4. Cloud-edge + cloud-enhancement overirradiance events at one of the eight Evaluation Sites reported in this paper, in which irradiance peaks over $1400 \mathrm{~W} / \mathrm{m}^{2}$ were measured for considerably long (min) periods, as shown in Table 1.

Measuring environmental and operational PV arrays electrical parameters at the individual PV string level, and at 1-s time resolution at all these sites leads to very large amounts of data, which have to be verified and qualified every day. This very high time-resolution was chosen in order to be able to detect and evaluate fast-changing environmental conditions (particularly irradiance, which was measured with Kipp and Zonen SMP11 pyranometers), and their influence on the response and performance of PV devices operating in a utility-scale PV power plant environment. The decision of measuring all parameters at the 1-s time resolution was made in the context of our previous experience with solar irradiance variations in a sunbelt region in contrast with that in higher latitude climates [13], and the effects of a larger fraction of solar energy availability at higher irradiances on PV generator inverter sizing $[13,18]$.

\section{Results and discussions}

Cloud-edge and cloud enhancement effects on solar irradiance at ground level have been previously reported in the literature [1]. Figure 3 shows an example with both effects taking place simultaneously at one of the eight ES reported in this paper, and Table 1 shows for the same site all the overirradiance events measured over nearly 2 years. The highest irradiance measurement reported in the literature so far is $1833 \mathrm{~W} / \mathrm{m}^{2}$ [3], measured at a $3400 \mathrm{~m}$ altitude site in the Ecuador Andes region, where the installation of utility-scale PV power plants in unlikely to take place for many obvious reasons. The highest irradiance peak measured at one of our eight ES, and where large-scale PV power plants are expected to be 


\section{Second x 10 minutes resolution of solar irradiance measurements}

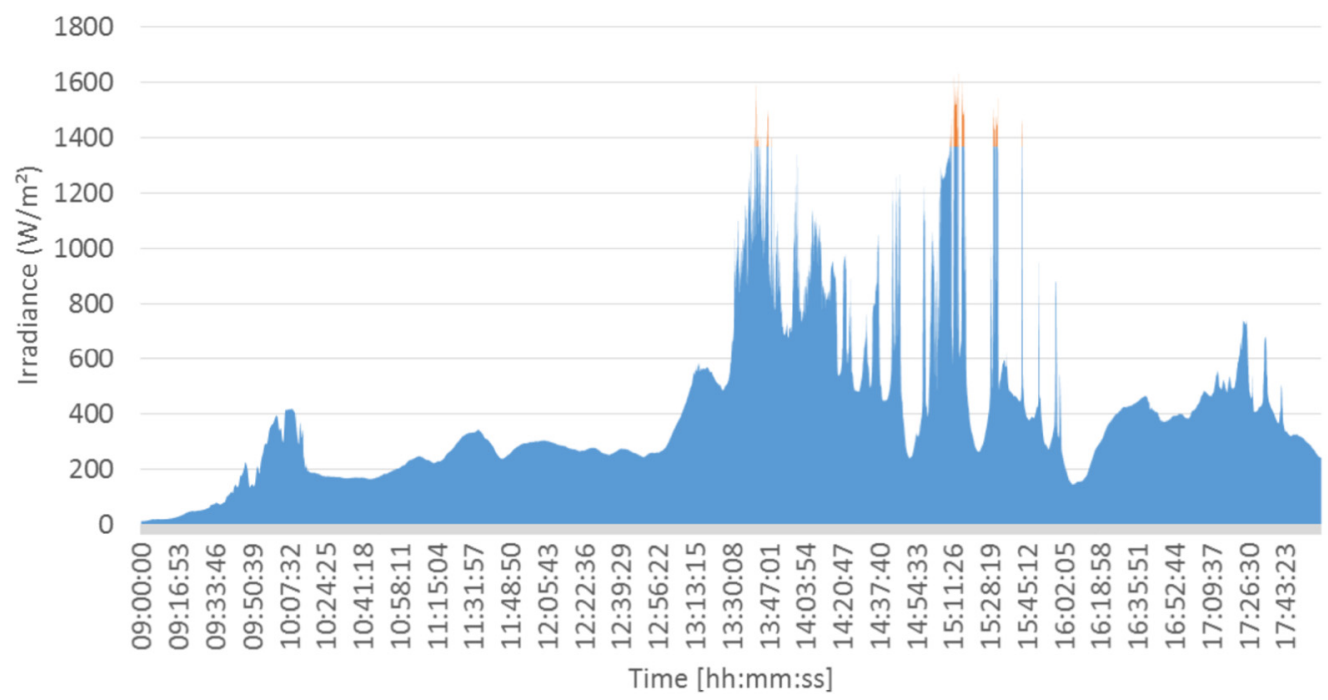

Fig. 5. One-second instant (blue and orange spiky curve) and 10-min averages (light-orange shadow smooth curve) solar irradiance measurements at one of the eight Evaluation Sites reported in this paper. The high irradiance peaks tend to disappear when data is averaged at 10 -min intervals.

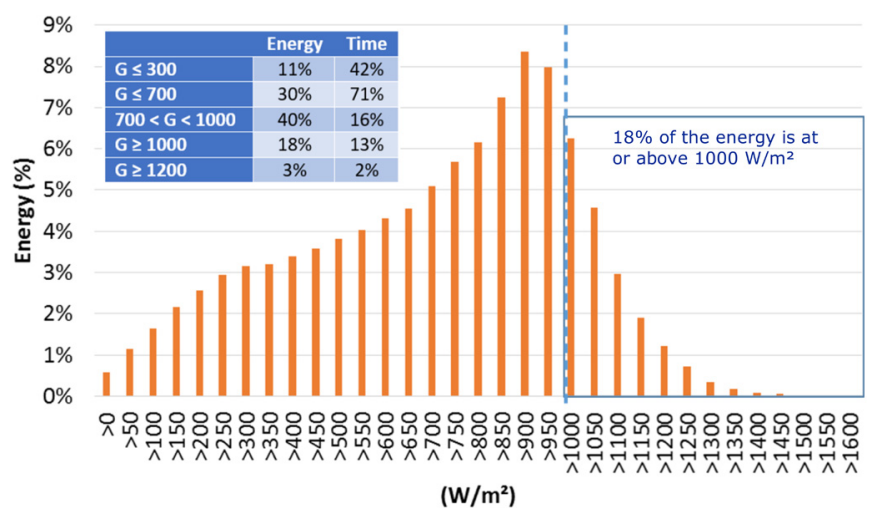

Fig. 6. Distribution of solar irradiation at $50 \mathrm{~W} / \mathrm{m}^{2}$ bins, measured at 1-s time resolution at one of the eight Evaluation Sites reported in this paper, showing that a considerable fraction $(18 \%)$ of the irradiation is at or above one sun or $1000 \mathrm{~W} / \mathrm{m}^{2}$ irradiance.

installed in Brazil in the near future, was $1823 \mathrm{~W} / \mathrm{m}^{2}$. While this extreme overirradiance event only lasted a few seconds, we have also recorded other overirradiance events which lasted many minutes as shown in Figure 4, and which can lead to deleterious consequences to the operation and maintenance of PV power plants, as we will further discuss. These overirradiance events can only be detected if solar irradiance is measured at a high time resolution with highquality, fast pyranometers, and we suspect that it might take place in many other sites throughout the globe. Figure 5 shows how lower time resolution measurements of solar irradiances mask overirradiance events. Averaging our 1-s measurements at 10-min intervals hides valuable information on irradiance peaks, and leads to misleading conclusions on the true solar irradiation resource availability at a particular site.
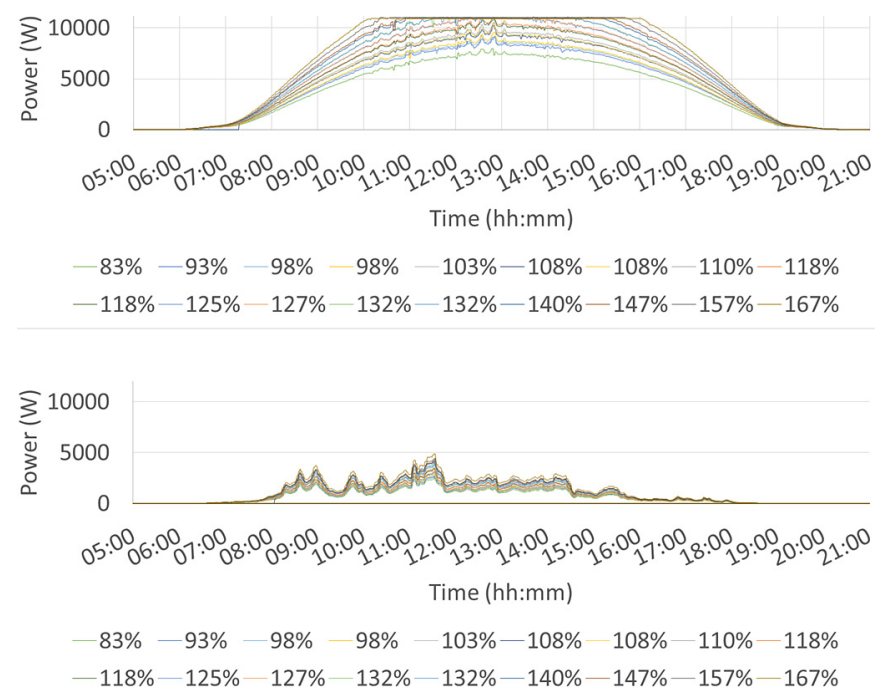

Fig. 7. Distribution of the output power (W) over a sunny (top set of curves) and a cloudy (bottom set of curves) day of 15 identical $10 \mathrm{~kW}$ string inverters with different ILRs (Inverter Loading Ratios), showing the clipping of power that takes place in sunny days when inverters are undersized (high ILRs).

Typical PV module manufacturer technical specifications include information on the "maximum series fuse rating", and designing a PV array with a fuse rated above this maximum value will lead to voiding the PV module warranty. At most sites where PV plants in Brazil will operate, ambient temperatures and irradiation levels are high, and the string boxes where the abovementioned fuses are installed can reach temperatures in excess of $70^{\circ} \mathrm{C}$, as we have routinely measured throughout this project. Fuse maximum currents are usually rated at $20^{\circ} \mathrm{C}$ operating temperatures, and at $70^{\circ} \mathrm{C}$ the typical derating factor is 0.7 . This fact, associated with overirradiance values in 

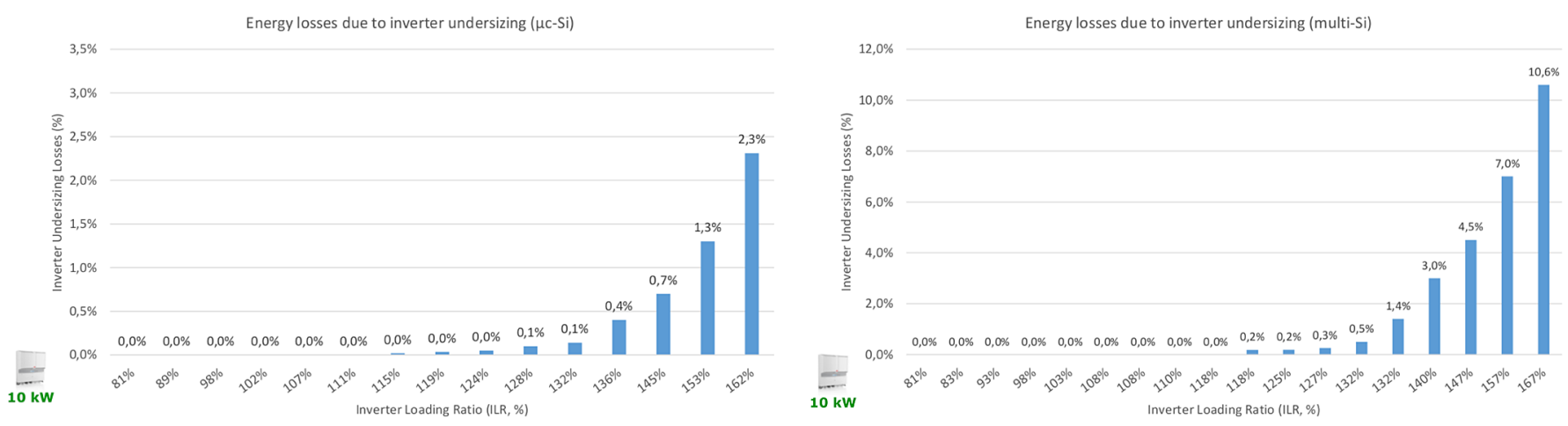

Fig. 8. Annual energy losses due to the Inverter Loading Ratio (ILR in \%) measured at the 3 MWp R\&D PV power plant for the thin film a-Si/ $\mu$ c-Si (left) and multi-Si (right) PV technologies.

excess of 1.4-1.6 suns for time spans in the minute-range, will result in conditions that will lead to the blowing of even slow-blow or time-delay fuses, if they are designed as per the PV module manufacturer's maximum series fuse rating specifications. We have not seen any previous reports in the literature of such a combination of effects, and based on these findings we can foresee a number of such events taking place in many of the large-scale PV power plants expected to be installed in Brazil starting in 2017. It is therefore recommended that PV module manufacturers reassess their maximum series fuse ratings in the light of this information.

Another important aspect that can be overlooked when measuring irradiance at low time resolutions, is the fact that a considerable portion of the solar irradiation incident at a site might be at high irradiance levels (at or above $1000 \mathrm{~W} / \mathrm{m}^{2}$ ), as shown in Figure 6 . This might lead to energy losses if the PV system inverter is undersized as typically recommended by traditional PV system design tools. In this project we have dedicated a portion of the 3 MWp R\&D PV power plant to study this effect, and have loaded a number of identical $10 \mathrm{~kW}$ string inverters with Inverter Loading Ratios (ILRs) ranging from about 80 up to about $170 \%$. Figure 7 shows the effect of inverter overloading (or undersizing) in both a sunny (top set of curves) and a cloudy (bottom set of curves) day at one of the eight ES reported in this paper. With the fast declining costs of PV modules, high ILRs are becoming common practice in PV system design, but the energy losses associated with this practice should not be neglected, as we will further show.

Figure 8 shows the energy losses associated with the loading of PV inverters in utility-scale PV power plants, in which PV array tilt and orientation are usually optimised when compared with rooftop PV, in which case PV modules are seldom optimally tilted and oriented. Figure 8 shows the evolution of the annual \% energy losses for the thin film a-Si $/ \mu \mathrm{c}-\mathrm{Si}$ (left) and for the traditional multi-Si (right) as the ILR is increased from around $80 \%$ up to around $170 \%$. While for the thin film a-Si $/ \mu \mathrm{c}-\mathrm{Si}$ the highest losses were $2.3 \%$ at $162 \%$ ILR, for multi-Si losses as high as $10.6 \%$ were measured for a $167 \%$ ILR (ILRs were not exactly the same for the two PV technologies due to specific string configurations that are dependent on PV module-type voltage and power characteristics). The differences in annual energy losses between the two PV technologies shown in Figure 8 contain a number of caveats, including the fact that the thin film a-Si $/ \mu \mathrm{c}-\mathrm{Si}$ PV modules were overrated by the manufacturer (which by the way is no longer in the PV module manufacturing scene), resulting in ILRs that reflect only the manufacturer's spec sheet, and not the true module rating at STC. A more detailed analysis is under way and will be published elsewhere, which might reveal that the energy losses of the a-Si $/ \mu \mathrm{c}-\mathrm{Si} \mathrm{PV}$ technology are in reality higher than those shown in Figure 8 (left).

\section{Conclusions}

We have briefly presented and discussed some of the issues evaluated in a long-term project on the performance assessment of different PV technologies for utility-scale applications in eight warm and sunny sites in Brazil. The main conclusions of this study include aspects related to PV system design of large-scale power plants in a warm and sunny environment, which are considerably different from the more traditional locations in which PV has been mostly deployed so far. Maximum series fuse ratings of PV modules and ILRs under the conditions described in this work (and predominant at many of the sites along the sunbelt countries which will dominate PV deployment in the future) were defined for more moderate operating conditions, where most of the $300 \mathrm{GWp}$ of PV installed in the planet so far operate. Extreme overirradiance events were measured and shown, and it can be speculated that high time resolution irradiance measurements in many sunny sites with considerable cloud movement will reveal this aspect to be a common feature at such sites. Due to the large amount of data this project has been producing over the last couple of years, more detailed accounts on each of the PV technologies deployed and the environmental and soiling conditions at each of the eight ES will be published elsewhere. The results presented in this paper give a concise overview of the main aspects that will have to be taken into account as utility-scale PV power plants start to emerge in large amounts in warm and sunny countries. 
The authors wish to acknowledge with thanks the Brazilian Electrical Energy Regulatory Agency ANEEL, as well as Tractebel Energia (now Engie Brasil Energia) and the 11 other cooperating electrical utility companies involved in project $\mathrm{PE}$ 0403-0027/2011 for sponsoring this project.

\section{References}

1. M.P. Almeida, R. Zilles, E. Lorenzo, Extreme overirradiance events in São Paulo, Brazil, Sol. Energy 110, 168 (2014)

2. R.C. Andrade, C. Tiba, Extreme global solar irradiance due to cloud enhancement in northeastern Brazil, Renew. Energy 86, 1433 (2016)

3. P. Emck, M. Richter, An upper threshold of enhanced global shortwave irradiance in the troposphere derived from field measurements in tropical mountains, J. Appl. Meteorol. Climatol. 47, 2828 (2008)

4. R.H. Inman, Y. Chu, C.F.M. Coimbra, Cloud enhancement of global horizontal irradiance in California and Hawaii, Sol. Energy 130, 128 (2016)

5. R.D. Piacentini, G.M. Salum, N. Fraidenraich, C. Tiba, Extreme total solar irradiance due to cloud enhancement at sea level of the NE Atlantic coast of Brazil, Renew. Energy 36, 409 (2011)

6. R. Tapakis, A.G. Charalambides, Enhanced values of global irradiance due to the presence of clouds in Eastern Mediterranean, Renew. Energy 62, 459 (2014)

7. G.H. Yordanow, T.O. Saetre, O.-M. Midtgard, Extreme overirradiance events in Norway: 1.6 suns measured close to $60^{\circ} \mathrm{N}$, Sol. Energy 115, 68 (2015)

8. G.H. Yordanow, A study of extreme overirradiance events for solar energy applications using NASA's I3RC Monte Carlo radiative transfer model, Sol. Energy 122, 954 (2015)

9. A.M. Pavan, A. Melit, A. de Pieri, The effect of soiling on energy production for large-scale photovoltaic plants, Sol. Energy 85, 1128 (2011)
10. C. Schill, S. Brachmann, M. Koehl, Impact of soiling on IVcurves and efficiency of PV-modules, Sol. Energy 112, 259 (2015)

11. S. Shrestha, M. Taylor, Soiling assessment in large-scale PV arrays, Solarpro 9, 20 (2016)

12. J. Tanesab, D. Parlevliet, J. Whale, T. Urmee, T. Pryor, The contribution of dust to performance degradation of $\mathrm{PV}$ modules in a temperate climate zone, Sol. Energy 120, 147 (2015)

13. B. Burger, R. Rüther, Inverter sizing of grid-connected photovoltaic systems in the light of local solar resource distribution characteristics and temperature, Sol. Energy 80, $32(2006)$

14. J.K. Copper, A.B. Sproul, S. Jarnason, Photovoltaic (PV) performance modelling in the absence of onsite measured plane of array irradiance (POA) and module temperature, Renew. Energy 86, 760 (2016)

15. E. Drury, A. Lopez, P. Denholm, R. Margolis, Relative performance of tracking versus fixed tilt photovoltaic systems in the USA, Progr. Photovolt.: Res. Appl. 22, 1302 (2014)

16. A.G. Gaglia, S. Lykoudis, A.A. Argiriou, C.A. Balaras, E. Dialynas, Energy efficiency of PV panels under real outdoor conditions - an experimental assessment in Athens, Greece, Renew. Energy 101, 236 (2017)

17. M. Lave, J. Kleissl, Optimum fixed orientations and benefits of tracking for capturing solar radiation in the continental United States. Renew. Energy 36, 1145 (2011)

18. J. Luoma, J. Kleissl, K. Murray, Optimal inverter sizing considering cloud enhancement, Sol. Energy 86, 421 (2012)

19. A.M. Nobre, S. Karthik, H. Liu, D. Yang, F.R. Martins, E.B. Pereira, R. Rüther, T. Reindl, H.M. Peters, On the impact of haze on the yield of photovoltaic systems in Singapore, Renew. Energy 89, 389 (2016)

20. T. Ozden, B.G. Akinoglu, R. Turan, Long term outdoor performances of three different on-grid PV arrays in central Anatolia - an extended analysis, Renew. Energy 101, 182 (2017)

21. R. Rüther, L.R. Nascimento, R. Campos, A.A. Montenegro, ANEEL R\&D Project Report PE-0403-0027/2011 (2016)

Cite this article as: Ricardo Ruther, Lucas Rafael do Nascimento, Rafael Antunes Campos, Performance assessment issues in utility-scale photovoltaics in warm and sunny climates, Renew. Energy Environ. Sustain. 2, 35 (2017) 